\title{
Influence of Channel Regulating Structures on the Transportation and Dissipation of Supersaturated Total Dissolved Gas
}

\author{
Yun Qing $\mathbb{D}^{1,},{ }^{1,2}$ Qian Ma $\mathbb{D D}^{3}{ }^{3}$ Ran Li, ${ }^{4}$ Xia Shen, ${ }^{4}$ XuJin Zhang, ${ }^{3}$ and LinFeng Han ${ }^{5}$ \\ ${ }^{1}$ College of River and Ocean Engineering, Chongqing Jiaotong University, Chongqing 400074, China \\ ${ }^{2}$ Chongqing Xike Consultation Center for Water Transport Engineering, Chongqing 400074, China \\ ${ }^{3}$ Chongqing Southwest Research Institute for Water Transport Engineering, Chongqing Jiaotong University, Chongqing 400074, \\ China \\ ${ }^{4}$ State Key Laboratory of Hydraulics and Mountain River Engineering, Sichuan University, Chengdu 610065, China \\ ${ }^{5}$ School of Civil Engineering, Chongqing Jiaotong University, Chongqing 400074, China
}

Correspondence should be addressed to Qian Ma; maggie@cqjtu.edu.cn

Received 6 November 2020; Revised 27 December 2020; Accepted 10 January 2021; Published 23 January 2021

Academic Editor: Loke Foong

Copyright (c) 2021 Yun Qing et al. This is an open access article distributed under the Creative Commons Attribution License, which permits unrestricted use, distribution, and reproduction in any medium, provided the original work is properly cited.

Bubble dissolution during the flood discharge creates high total dissolved gas (TDG) concentration zones downstream of the dams. The dissipation of supersaturated TDG is a very slow process. Thus, the elevated TDG may remain through the water body for hundreds of kilometers downstream and lead to gas bubble disease (GBD) and even mortality in fish. To improve the navigation conditions of waterways, dikes (i.e., a solid structure) of varied sizes and shapes are commonly constructed. However, this would affect the dissipation and transportation of the supersaturated TDG. It would significantly change the turbulence intensity and hydropressure of the flow, which dominates the dissipation of TDG. Therefore, TDG distribution in the waterway differs from that in the natural river. In this study, a numerical simulation of the TDG at the Yangtze River's upper reaches (one of the inland waterways in China) was conducted with the establishment of a two-dimensional TDG dissipation model. The effect of the dikes' size and shape was analyzed to assess the influence of the regulation structures on the dissipation and transportation of the supersaturated TDG. Meanwhile, simulation in the study area with the natural topography was also set as blank control. Based on that, impact evaluation of TDG supersaturation on fish under different simulation scenarios was made. This study can provide a scientific basis for reducing the adverse effect of supersaturated TDG in fish and the construction of ecological waterway therefore.

\section{Introduction}

A waterway is known as any navigable body of water. Along with the rapid pace of the Golden Waterway of Yangtze River and inland waterway construction, more and more giant cascade hydropower stations are built or to be built. However, during the discharge process, excess air would be entrained into the water and cause supersaturation of total dissolved gas (TDG) due to the variation of deep pressure head. Dissipation of supersaturated TDG is known as a slight process [1]. It will exist along the river for quite a long time, leading to gas bubble disease (GBD) or even death to fish [2-4]. During dam sluice of the Three Gorges, it was observed that TDG in section $600 \mathrm{~km}$ downstream, the dam was high above $117 \%$
[5]. The other side of channel construction is waterway regulation by dredging, reef explosion, and the construction of regulating structures. It may significantly change the flow condition and lead to a difference in TDG dissipation compared with the natural river [6-8]. Until now, there are plenty of research studies on the environmental effects of waterway regulating structures $[9,10]$, but few focused on the effect of channel regulating structures on the transportation and dissipation of supersaturated total dissolved gas. There are numerous studies performed on the dam and reservoir hydroenvironment models. Different studies are conducted for the environment sustainability concerns of things happening on rivers [11-15], hydrobased energy [16-20], soil [21], water [22], decontamination [23, 24], air/carbon- 
emission implications [25-33], precipitation [34], and evaporation [35-40]. Some geo-hydro-environmental-based studies that have been taken recently are tabulated in Table 1.

Lots of research works have been carried out for TDG dissipation [58-61]. It was found that the release of supersaturated TDG is related to the water depth. TDG dissipation can be accelerated with the decrease of water depth. Based on prototype observation of TDG dissipation in several rivers of China (e.g., Yangzi River, Yalong River, and Langtang River), Feng et al. [62] computed each river's release coefficient using the first-order kinetic process. It was found out that the release coefficient of supersaturated TDG downstream the Zipingpu Dam in Min River was $0.563 \mathrm{~h}^{-1}$ $\sim 0.650 \mathrm{~h}^{-1}$, which was larger than that in the river reach downstream the Three Gorges in the Yangzi River, $0.014 \mathrm{~h}^{-1}$ $\sim 0.020 \mathrm{~h}^{-1}$. The water depth downstream of the Three Gorges during the flood discharge period was much deeper than that of the Min River. It was also observed that TDG observation in the reservoir of Dachaoshan and the natural reach downstream was $0.04 \% / \mathrm{km}$ and $0.26 \% / \mathrm{km}$, respectively, which means variation of water depth has a significant effect on TDG dissipation. Water temperature is also a key factor in TDG dissipation. TDG supersaturation is an unstable nonequilibrium state. The excess gas in the water will be released slowly to regain the equilibrium state. Temperature is one of the critical factors influencing gas solubility. Ou et al. [54] researched the influence of temperature on the release of supersaturated TDG. It was found that, under certain conditions of pressure and turbulence intensity, the coefficient of $28^{\circ} \mathrm{C}$ water temperature was about four times under $4^{\circ} \mathrm{C}$. Moreover, wind can significantly promote the release of supersaturated TDG, and the quantitative relation of release coefficient and wind speed was developed by Huang et al. [63]. Besides, turbulence intensity, water-sediment concentration, and river morphology also significantly influence the release rate of TDG [64].

Based on research results of the release coefficient of TDG, a series of calculation models for TDG release were established and were used to simulation TDG dissipation in the natural river. Perkins and Richmond [65] developed a depthaveraged 2-D model to study TDG saturation distribution downstream the Bonneville Dam and the Ice Harbor Dam. $\mathrm{Ma}$ et al. [53] studied operation regulation of water replenishment to deduce supersaturated TDG through a 1-D unsteady TDG model. Shen et al. [66] established a depth-averaged, two-dimensional model of TDG dissipation at a river confluence and explored shelter construction for fish at the confluence of a river to avoid the effect of TDG supersaturation. Feng et al. [62] carried out a width-averaged 2-D TDG model for numerical simulation of water temperature and TDG distribution in a large reservoir based on the 2-D water temperature model. Among those studies mentioned above, the river reaches were gentrified, while only the natural topography was considered. However, the channel regulating structures will change the topographic condition to a greater extent, and the flow condition would not be the same anymore. For now, little research was conducted about the effect of the channel regulating structures on TDG dissipation. The present work examined the distribution of supersaturated TDG near the regulating structures in a numerical simulation. Potential intervention for enlarging the area of low TDG was studied in the model.

\section{Mathematical Model}

2.1. Numerical Model. A depth-averaged, 2D model applying the Reynolds-averaged, hydrostatic (shallow-water) Navier-Stokes equations was used to simulate the transport of TDG in a waterway with the contribution of the regulating structures:

$$
\begin{aligned}
\frac{\partial \zeta}{\partial t}+\frac{\partial(h+\zeta) u}{\partial x}+\frac{\partial(h+\zeta) v}{\partial y}= & , \\
\frac{\partial u}{\partial t}+u \frac{\partial u}{\partial x}+v \frac{\partial u}{\partial y}= & -g \frac{\partial \zeta}{\partial x}+v_{t}\left(\frac{\partial^{2} u}{\partial x^{2}}+\frac{\partial^{2} u}{\partial y^{2}}\right) \\
& +\frac{1}{\rho(h+\zeta)}\left(\tau_{s x}-\tau_{b x}\right), \\
\frac{\partial \nu}{\partial t}+u \frac{\partial v}{\partial x}+v \frac{\partial v}{\partial y}= & -g \frac{\partial \zeta}{\partial y}+v_{t}\left(\frac{\partial^{2} v}{\partial x^{2}}+\frac{\partial^{2} v}{\partial y^{2}}\right) \\
& +\frac{1}{\rho(h+\zeta)}\left(\tau_{s y}-\tau_{b y}\right) \\
\frac{\partial h G}{\partial t}+u \frac{\partial h G}{\partial x}+v \frac{\partial h G}{\partial y}= & \frac{\partial}{\partial x}\left(v_{t} \frac{\partial h G}{\partial x}\right) \\
& +\frac{\partial}{\partial y}\left(v_{t} \frac{\partial h G}{\partial y}\right)+h S_{C}
\end{aligned}
$$

where $\zeta$ is the difference between the surface elevation and the mean depth, $t$ is the time, $h$ is the mean water depth, $u$ and $v$ are the depth-averaged flow velocity components in the $x$ - and $y$-direction, respectively, $g$ is the acceleration of gravity, $\rho$ is the water density, $v_{t}$ is an eddy viscosity coefficient, $\tau_{s}$ and $\tau_{b}$ are the surface wind stress and the river bottom friction, $G$ is the concentration of TDG, and $S_{C}=$ $-k_{\mathrm{TDG}} G$ is the sink dissipation of TDG, where $k_{\mathrm{TDG}}$ is the dissipation coefficient of the supersaturated TDG.

2.2. Model Verification. The numerical model for hydrodynamics in our work was validated by Wang et al. [4]. To validate the scalar transport model, we developed a simulation according to a laboratory experiment by Kang [15]. In this experiment, salt concentrations were used as a conservative tracer to identify tributary water. The model grid used 19577 grid cells in an unstructured triangular mesh, as shown in Figure 1. Experimental data and the simulation results are compared in Figure 2. The error values at the measurement points between model and experiment range from $2.9 \%$ to $9.8 \%$, which is a reasonable agreement.

2.3. Study Site. As a study site, we use a reach of the Jialing River (China) $3 \mathrm{~km}$ downstream of the Caojie Dam and stretches $4 \mathrm{~km}$. There exist the typical dry rapids, Gouzuwan. 
TABLE 1: Some recent geo-hydro-environmental-based studies and their main achievements.

\begin{tabular}{|c|c|c|}
\hline Authors & Study area & Main achievements \\
\hline Feng et al. [41] & Region of Tibetan plateau in China & Implications for natural environmental response to human activities \\
\hline Han et al. [42] & China & $\begin{array}{l}\text { Pathways for cleaner electricity production, reviews on energy consumption, } \\
\text { economic cost, and environmental impact }\end{array}$ \\
\hline He et al. [43] & Beaver county, Pennsylvania & $\begin{array}{l}\text { Energy-water nexus for identifying environmental impacts during shale gas } \\
\text { operations under stochastic input }\end{array}$ \\
\hline He et al. [44] & China & $\begin{array}{c}\text { Evaluate the ecological vulnerability, environmental and social management, } \\
\text { ecological conservation potential impacts of natural, social, economic, } \\
\text { environmental pollution, and human health elements }\end{array}$ \\
\hline Liu et al. [45] & Guangzhou, China & $\begin{array}{l}\text { Establish an environmental assessment model of construction and demolition } \\
\text { waste }\end{array}$ \\
\hline Lu et al. [46] & Western Europe & $\begin{array}{l}\text { Policy recommendations, consideration of socioeconomic, geo-hydrological, } \\
\text { climate, and groundwater factors study on the aquifer thermal energy storage }\end{array}$ \\
\hline Wang et al. [47] & $\begin{array}{l}\text { Shaanxi province, Northwest } \\
\text { China }\end{array}$ & Hydrological model and assessing the environmental impact of slope failure \\
\hline Chen et al. [48] & China & Water pollution for agricultural irrigation resources \\
\hline Chen et al. [49] & United States & $\begin{array}{l}\text { Multicriteria design of shale-gas-water supply chains and production systems } \\
\text { towards optimal life cycle economics and greenhouse gas emissions under } \\
\text { uncertainty }\end{array}$ \\
\hline Chen et al. [50] & China and the United States & Water management in gas supply chains \\
\hline $\begin{array}{l}\text { Cheng et al. [51], } \\
\text { He et al. [26], } \\
\text { He et al. [52], }\end{array}$ & $\begin{array}{l}\text { Pennsylvania and West Virginia; } \\
\text { United States; China }\end{array}$ & $\begin{array}{c}\text { Optimal water resources management, high consumption of water resources } \\
\text { rowing greenhouse gas }\end{array}$ \\
\hline $\begin{array}{l}\text { Ma et al. [53], } \\
\text { Ou et al. [54] }\end{array}$ & China & Reduce supersaturated total dissolved gas in riverine wetlands \\
\hline
\end{tabular}

Piotrowski et al.

[55],

Tyrrell and

George [56],

Yang et al. [57]

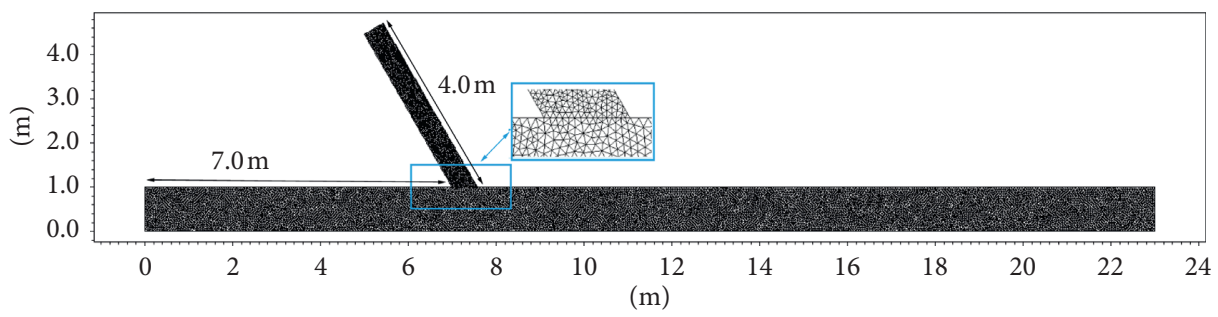

FIgURe 1: Model grids in the validation domain for the numerical simulation of the Kang flume experiments.

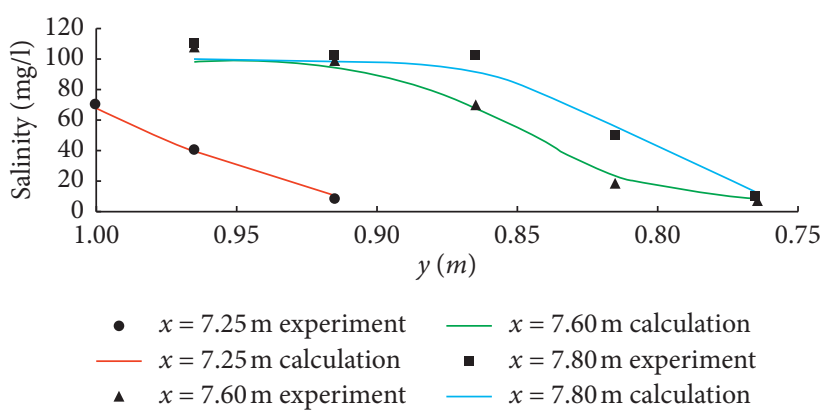

Figure 2: Comparison of the salinity between the model and the experiment. 
To improve the navigation condition in this reach, waterway regulations were designed in 2009, consisting of cutoff works, reef explosion, dredging, and groins construction, as shown in Figure 3.

2.4. General Conditions and Boundary Conditions. The Jialing River is itself a tributary of the Yangzi River in Chongqing Province, China. The dam height of the Caojie Navigation-Power junction is $56.0 \mathrm{~m}$. Its average water level is $203.00 \mathrm{~m}$ above the sea level. The typical storage capacity is $7.54 \times 10^{8} \mathrm{~m}^{3} / \mathrm{s}$. The flood discharge structures include five scouring sluices and 15 spillways with the use of bottom-flow dissipation. For the maximum navigable discharge, $15,000 \mathrm{~m}^{3} / \mathrm{s}$, the supersaturated TDG level is $131 \%$ [15]. Power flow rate is $3,054 \mathrm{~m}^{3} / \mathrm{s}$ with TDG saturation of approximately $100 \%$. Because of the flow rates' disparities, full mixing of the floods discharge with the power flow reduces the $131.0 \%$ predicted TDG supersaturation down to $125 \%$. Water flow with supersaturated TDG high above $110 \%$ can be lethal to fish. Thus, the effect of waterway relation on the dissipation of TDG is desirable. Field measurements for velocity, mixing, and TDG in the study are not available. So, our work focuses on comparing a baseline numerical simulation of the known river morphology with the simulation of waterway regulation to examine how these works change the TDG distribution.

2.4.1. Domain and Mesh Division. The computation domain (Figure 3) in the Jialing River extends approximately $3.0 \mathrm{~km}$. The unstructured grid used 195,625 approximately uniform triangular elements with an average area of $25 \mathrm{~m}^{2}$ in each element. The flow rate of the flood discharge and the power flow rate were $11,946 \mathrm{~m}^{3} / \mathrm{s}$ and $3054 \mathrm{~m}^{3} / \mathrm{s}$, respectively. The TDG saturation was $125.0 \%$ and $100.0 \%$, respectively.

2.4.2. Parameter Determination. The Smagorinsky coefficient used for the turbulence model was 0.28 , and the Prandtl constant value was 1 . The Manning coefficient for bottom roughness was set as 0.03 . These values are the same as those used in the validation experiment (Section 2.2). The dissipation coefficient of the supersaturated TDG was set as $1.72 \times 10^{-5} \mathrm{~s}^{-1}$, which matches field observation results in the Yangzi River.

\section{Results and Discussion}

3.1. Prediction Results. Water depth and velocity are the main factors that affect the dissipation of supersaturated TDG. The simulation results of the flow field under different calculation conditions are compared in Figure 4. A noticeable difference in water depth and velocity occurred due to the topographical boundary change, especially in the area where three groins were constructed. Water depth before the one \# groin and the four \# groins increased to $14.5 \mathrm{~m}$ and $14.2 \mathrm{~m}$, respectively, while those before the regulation were $13.1 \mathrm{~m}$ and $13.0 \mathrm{~m}$. Due to water contraction induced by the groins, the mainstream was narrowed, and the maximum velocity increased to $4.8 \mathrm{~m} / \mathrm{s}$, which was $1.6 \mathrm{~m} / \mathrm{s}$ larger than that before the regulation. The area downstream of the groins turned into the recirculation zone, and the velocity decreased significantly. The recirculation zones in $A-1$ and $A-2$ were $109,466 \mathrm{~m}^{2}$ and $75,145 \mathrm{~m}^{2}$, which could increase the detention time of the supersaturated TDG and provided shelter for fishes.

Figure 5 shows the simulation results of TDG distribution in the regulated waterway compared with that in the natural river. TDG saturation of the mainstream was only reduced to $122.1 \%$ in the natural river while that after the regulation was $122.0 \%$, which was nearly the same. TDG dissipation is a slight process; with a large flow rate, TDG saturation in the mainstream is dominated by the inflow boundary. However, a significant difference occurred in the area where the groins were constructed. Due to the water contraction and the recirculation zones induced by the groins, the mainstream was narrowed. The diffusing width of the polluted zone with TDG saturation less than $120 \%$ enlarged to $219 \mathrm{~m}$ from $173 \mathrm{~m}$, which extended to $45.7 \%$ of the outlet section's width.

3.2. Effect for Fish. According to the abovementioned simulation results, there will not be a significant difference in TDG saturation in the mainstream in the computational domain due to the large flow rate. However, the recirculation zones and the riverbank, as shown in Figure 5, increase the detention time of supersaturated TDG, which was beneficial for the release process. Thus, the waterway regulation's construction enlarged the area of low-saturation along the riverbank where it can provide a shelter for fish. It can protect the fish from the damaging effects of TDG supersaturation. According to the area statistics of TDG saturation at a different level before and after the waterway regulation, as listed in Table 2, the size of the saturation regions of TDG saturation less than $110 \%, 115 \%$, and $120 \%$ increased $36,679 \mathrm{~m}^{2}, 56,477 \mathrm{~m}^{2}, 161,135 \mathrm{~m}^{2}$, respectively. Based on research results of fish tolerance to fish, the river reaches the Jialing River after the waterway regulation was expected to meet the space requirements necessary for fish to avoid the supersaturation damaging effect of TDG.

The numerical simulation study shows that waterway regulation may be beneficial to the river's ecological function as far as TDG supersaturation is concerned. The fundamental idea is installing groins along the riverbank to control the distribution of low TDG water downstream the dikes and create a low TDG refuge that otherwise might not occur because of the high-water flow rate or velocities of the natural river. Note that the waterway regulation varies with the waterway topography and operation features of the hydropower station nearby. The effect of waterway regulation on the flow field is different from the distribution of TDG. To reduce the adverse effect of waterway regulation on the river ecosystem and maximize its benefits, we need to investigate how 3D turbulence at the local area where the regulation measures conducted affects the dissipation rate of supersaturated TDG. It is of theoretical value and practical significance in developing eco-environmentally friendly 


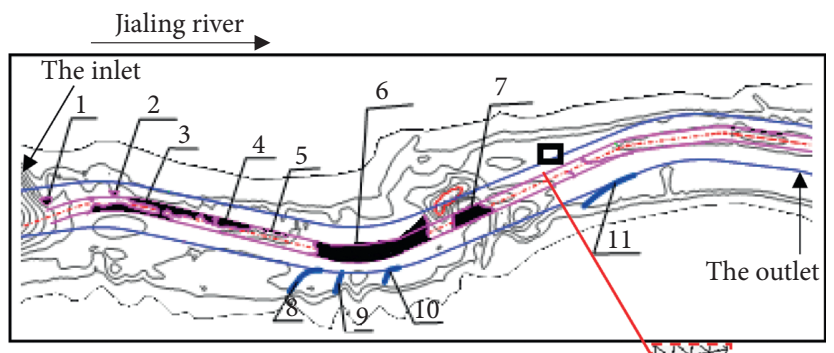

1, 2: cutoff work. 3: Reef explosion and dredging.

4, 5, 7: Reef explosion. 6: Dredging. 8, 9, 10, 11: groins

FIGURE 3: Sketch of the computational domain and the regulatory scheme for the channel.

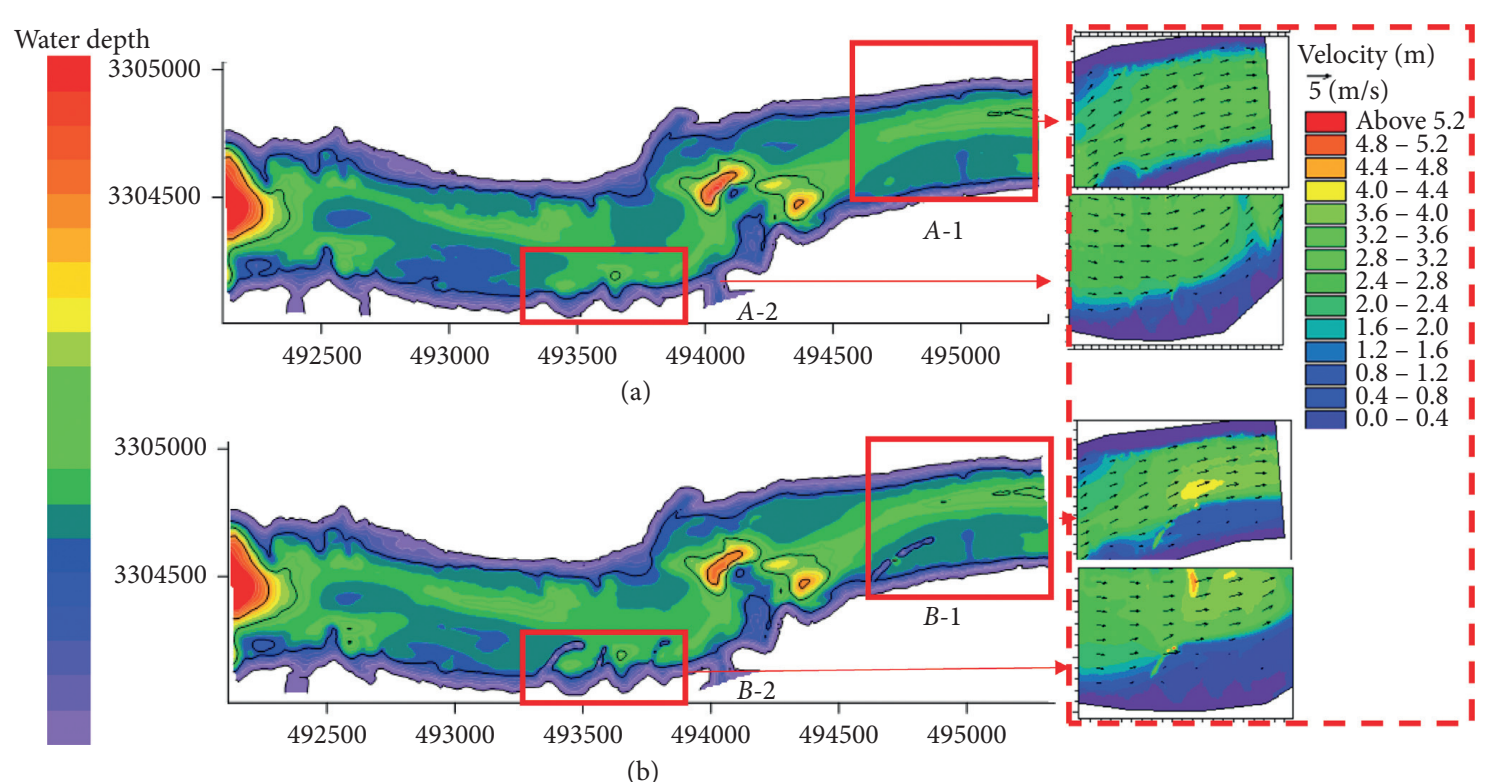

FIgURE 4: Comparison of the water depth and the local velocity distribution. (a) Before the regulation. (b) After the regulation.

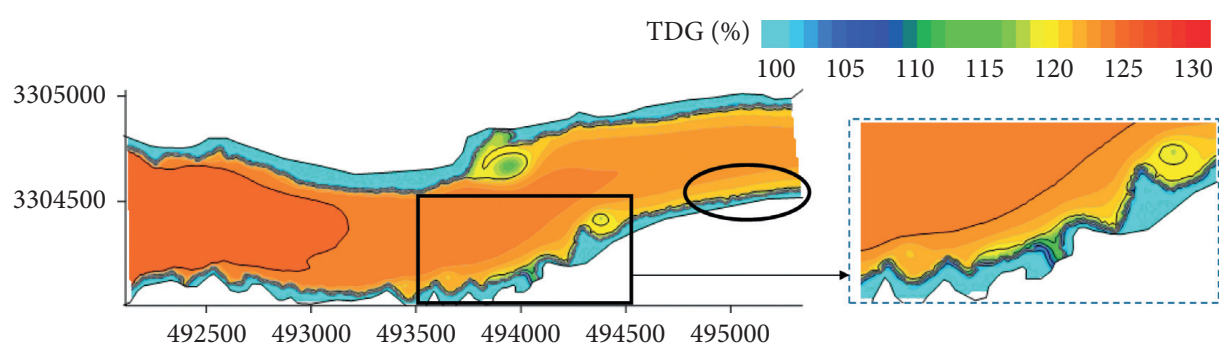

(a)

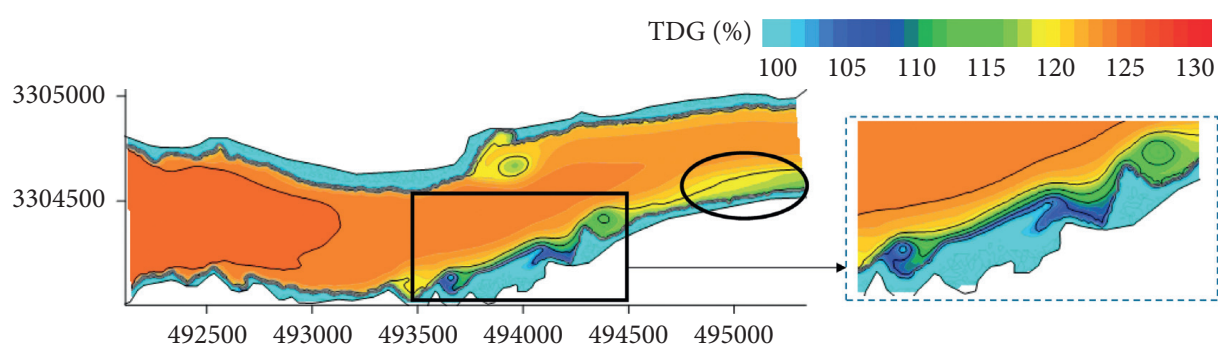

(b)

FIGURE 5: Comparison of TDG distribution. (a) Before the regulation. (b) After the regulation. 
TABLE 2: Area statistics of different TDG levels before and after the waterway regulation.

\begin{tabular}{lccc}
\hline Case & \multicolumn{3}{c}{ TDG $(\%)$} \\
& $<110$ & $<115$ & $<120$ \\
\hline Before regulation & 447,695 & 454,914 & 533,193 \\
After regulation & 487,374 & 511,391 & 694,328 \\
\hline
\end{tabular}

waterway. In this sense, knowledge of how the transportation and dissipation of supersaturated TDG can be controlled is vital for protecting the fishes from the destructive effect of TDG supersaturation. Due to the complexity of the inland waterway, the effect of waterway regulation needs to be further studied in combination with waterway regulation design and an assessment of local fish survival.

\section{Conclusions}

A depth-averaged, two-dimensional model for TDG transportation and dissipation was developed in this paper. A flume experiment verified the model, and the results matched well. A numerical simulation of TDG in the Jialing River's river reach, where the waterway regulation measures were constructed, was conducted. Besides, simulation in the study area with the natural topography was also set to analyze the effect of the waterway regulation on the transportation and dissipation of TDG. The simulation results showed reef explosion and dredging in the study site did not have a noticeable effect on the distribution of TDG since TDG release is a slight process and the inflow boundary condition dominated that of the mainstream. However, the groins' construction narrowed the mainstream, and the recirculation area was formed downstream of the dam in a wide area. It can increase the detention time of water flow with supersaturated TDG and allowed the low-saturation region to remain in a particular range. Thus, the area with low saturation of TDG was enlarged. This area could provide refuge space for fish to avoid the damaging of supersaturated TDG. This study provides a scientific basis for waterway regulation on the river ecosystem and some mitigation measures to reduce TDG supersaturation.

\section{Data Availability}

The data used to support the findings of this study are currently under embargo while the research findings are commercialized. Requests for data, 6/12 months after publication of this article, will be considered by the corresponding author.

\section{Disclosure}

The paper was presented in the 13th International Conference on Hydroscience and Engineering Proceedings.

\section{Conflicts of Interest}

The authors declare that they have no conflicts of interest.

\section{Acknowledgments}

This work was supported by the Science and Technology Research Program of Chongqing Municipal Education Commission (Grant no. KJQN20200716) and the National Natural Science Foundation of China (Grant nos. 2016YFC0402004 and 52009014).

\section{References}

[1] R. Li, J. Li, K. Li, Y. Deng, and J. Feng, "Prediction for supersaturated total dissolved gas in high-dam hydropower projects," Science in China Series E: Technological Sciences, vol. 52, no. 12, pp. 3661-3667, 2009.

[2] W. Kirkland, Total Dissolved Gas Biological Effects, First draft to Public Utility District No. 1 of Chelan County Wenatchee, Wenatchee, WA, USA, 2001.

[3] J. E. Smiley, M. A. Drawbridge, M. S. Okihiro, and R. S. Kaufmann, "Acute effects of gas supersaturation on juvenile cultured White Seabass," Transactions of the American Fisheries Society, vol. 140, pp. 1269-1276, 2001.

[4] Y. Wang, R. Liang, Y. Tuo, K. Li, and B. Hodges, "Tolerance and avoidance behavior towards gas supersaturation in rock CarpProcypris rabaudiwith a history of previous exposure," North American Journal of Aquaculture, vol. 77, no. 4, pp. 478-484, 2015.

[5] J. Feng, R. Li, K. Li, J. Li, and L. Qu, "Study on release process of supersaturated total dissolved gas downstream of high dam," Journal of Hydroelectric Engineering, vol. 29, pp. 7-12, 2010.

[6] T. Akihiro and N. Yoshiro, "Flow structures in spur-dike region by using PIV method," Journal of the Visualiza- Tion Society of Japan, vol. 19, no. 1, pp. 413-416, 1999.

[7] R. Mayerle, S. S. Y. Wang, and F. M. Toro, "Verification of a three-dimensional numerical model simulation of the flow in the vicinity of spur dikes," Journal of Hydraulic Research, vol. 33, no. 2, pp. 243-256, 1995.

[8] S.-S. Shih, H.-Y. Lee, and C.-C. Chen, "Model-based evaluations of spur dikes for fish habitat improvement: a case study of endemic species Varicorhinus barbatulus (Cyprinidae) and Hemimyzon formosanum (Homalopteridae) in Lanyang River, Taiwan," Ecological Engineering, vol. 34, no. 2, pp. 127-136, 2008.

[9] Z.-p. Gu, R. Akahori, and S. Ikeda, "Study on the transport of suspended sediment in an open channel flow with permeable spur dikes," International Journal of Sediment Research, vol. 26, no. 1, pp. 96-111, 2011.

[10] M. Fazli, M. Ghodsian, and S. A. A. S. Neyshabouri, "Scour and flow field around a spur dike in a $90^{\circ}$ bend," International Journal of Sediment Research, vol. 23, no. 1, pp. 56-68, 2008.

[11] Z. Lyu, J. Chai, Z. Xu, Y. Qin, and J. Cao, "A comprehensive review on reasons for tailings dam failures based on case history," Advances in Civil Engineering, vol. 2019, Article ID 4159306, 1 page, 2019.

[12] P. Tian, H. Lu, W. Feng, Y. Guan, and Y. Xue, "Large decrease in streamflow and sediment load of Qinghai-Tibetan Plateau driven by future climate change: a case study in Lhasa River Basin," Catena, vol. 187, Article ID 104340, 2020.

[13] C. Zhang and H. Wang, "Swing vibration control of suspended structures using the active rotary inertia driver system: theoretical modeling and experimental verification," Structural Control and Health Monitoring, vol. 27, no. 6, p. e2543, 2020. 
[14] K. Zhang, G. B. Ruben, X. Li et al., "A comprehensive assessment framework for quantifying climatic and anthropogenic contributions to streamflow changes: a case study in a typical semi-arid North China basin," Environmental Modelling \& Software, vol. 128, Article ID 104704, 2020.

[15] X. Hu, H.-Y. Chong, and X. Wang, "Sustainability perceptions of off-site manufacturing stakeholders in Australia," Journal of Cleaner Production, vol. 227, pp. 346-354, 2019.

[16] Y. Deng, T. Zhang, B. K. Sharma, and H. Nie, "Optimization and mechanism studies on cell disruption and phosphorus recovery from microalgae with magnesium modified hydrochar in assisted hydrothermal system," Science of The Total Environment, vol. 646, pp. 1140-1154, 2019.

[17] L. Jia, B. Liu, Y. Zhao et al., "Structure design of MoS2@Mo2C on nitrogen-doped carbon for enhanced alkaline hydrogen evolution reaction," Journal of Materials Science, vol. 55, no. 34, pp. 16197-16210, 2020.

[18] T. Zhang, X. He, Y. Deng et al., "Swine manure valorization for phosphorus and nitrogen recovery by catalytic-thermal hydrolysis and struvite crystallization," Science of The Total Environment, vol. 729, Article ID 138999, 2020.

[19] T. Zhang, X. Wu, X. Fan, D. C. W. Tsang, G. Li, and Y. Shen, "Corn waste valorization to generate activated hydrochar to recover ammonium nitrogen from compost leachate by hydrothermal assisted pretreatment," Journal of Environmental Management, vol. 236, pp. 108-117, 2019.

[20] T. Zhang, X. Wu, H. Li, D. C. W. Tsang, G. Li, and H. Ren, "Struvite pyrolysate cycling technology assisted by thermal hydrolysis pretreatment to recover ammonium nitrogen from composting leachate," Journal of Cleaner Production, vol. 242, Article ID 118442, 2020.

[21] K. Zhang, Q. Wang, L. Chao et al., "Ground observationbased analysis of soil moisture spatiotemporal variability across a humid to semi-humid transitional zone in China," Journal of Hydrology, vol. 574, pp. 903-914, 2019.

[22] X. Li, R. Zhang, X. Zhang, P. Zhu, and T. Yao, "Silver-catalyzed decarboxylative allylation of difluoroarylacetic acids with allyl sulfones in water," Chemistry-An Asian Journal, vol. 15, no. 7, pp. 1175-1179, 2020.

[23] L. Liu, J. Li, F. Yue et al., "Effects of arbuscular mycorrhizal inoculation and biochar amendment on maize growth, cadmium uptake and soil cadmium speciation in Cd-contaminated soil," Chemosphere, vol. 194, pp. 495-503, 2018.

[24] D. Zhang, X. Han, H. Wang, Q. Yang, and J. Yan, "Experimental study on transient heat/mass transfer characteristics during static flash of aqueous $\mathrm{NaCl}$ solution," International Journal of Heat and Mass Transfer, vol. 152, Article ID 119543, 2020.

[25] Y. Chen, L. He, Y. Guan, H. Lu, and J. Li, "Life cycle assessment of greenhouse gas emissions and water-energy optimization for shale gas supply chain planning based on multi-level approach: case study in Barnett, Marcellus, Fayetteville, and Haynesville shales," Energy Conversion and Management, vol. 134, pp. 382-398, 2017.

[26] L. He, Y. Chen, and J. Li, "A three-level framework for balancing the tradeoffs among the energy, water, and airemission implications within the life-cycle shale gas supply chains," Resources, Conservation and Recycling, vol. 133, pp. 206-228, 2018.

[27] Z. Su, E. Liu, Y. Xu, P. Xie, C. Shang, and Q. Zhu, "Flow field and noise characteristics of manifold in natural gas transportation station," Oil \& Gas Science and Technology - Revue D'IFP Energies Nouvelles, vol. 74, p. 70, 2019.
[28] W. Yang, D. Pudasainee, R. Gupta, W. Li, B. Wang, and L. Sun, "An overview of inorganic particulate matter emission from coal/biomass/MSW combustion: sampling and measurement, formation, distribution, inorganic composition and influencing factors," Fuel Processing Technology, vol. 2020, Article ID 106657, 2020.

[29] Y. Yang, J. Liu, J. Yao et al., “Adsorption behaviors of shale oil in kerogen slit by molecular simulation," Chemical Engineering Journal, vol. 387, Article ID 124054, 2020.

[30] W. Zhang, "Parameter adjustment strategy and experimental development of hydraulic system for wave energy power generation," Symmetry, vol. 12, no. 5, p. 711, 2020.

[31] X. Zhao, Y. Ye, J. Ma, P. Shi, and H. Chen, "Construction of electric vehicle driving cycle for studying electric vehicle energy consumption and equivalent emissions," Environmental Science and Pollution Research, vol. 27, no. 30, pp. 37395-37409, 2020.

[32] L. Liu, D. Li, Y. Ma, H. Shen, S. Zhao, and Y. Wang, "Combined application of arbuscular mycorrhizal fungi and exogenous melatonin alleviates drought stress and improves plant growth in tobacco seedlings," Journal of Plant Growth Regulation, 2020.

[33] Q. Lv, H. Liu, D. Yang, and H. Liu, "Effects of urbanization on freight transport carbon emissions in China: common characteristics and regional disparity," Journal of Cleaner Production, vol. 211, pp. 481-489, 2019.

[34] L. Chao, K. Zhang, Z. Li, Y. Zhu, J. Wang, and Z. Yu, "Geographically weighted regression based methods for merging satellite and gauge precipitation," Journal of $\mathrm{Hy}$ drology, vol. 558, pp. 275-289, 2018.

[35] B. Keshtegar, S. Heddam, A. Sebbar, S.-P. Zhu, and N.-T. Trung, "SVR-RSM: a hybrid heuristic method for modeling monthly pan evaporation," Environmental Science and Pollution Research, vol. 26, no. 35, pp. 35807-35826, 2019.

[36] O. Kisi and S. Heddam, "Evaporation modelling by heuristic regression approaches using only temperature data," $\mathrm{Hy}$ drological Sciences Journal, vol. 64, no. 6, pp. 653-672, 2019.

[37] A. Ghaemi, M. Rezaie-Balf, J. Adamowski, O. Kisi, and J. Quilty, "On the applicability of maximum overlap discrete wavelet transform integrated with MARS and M5 model tree for monthly pan evaporation prediction," Agricultural and Forest Meteorology, vol. 278, Article ID 107647, 2019.

[38] B. Zhang, D. Xu, Y. Liu, F. Li, J. Cai, and L. Du, "Multi-scale evapotranspiration of summer maize and the controlling meteorological factors in north China," Agricultural and Forest Meteorology, vol. 216, pp. 1-12, 2016.

[39] D. K. Roy, R. Barzegar, J. Quilty, and J. Adamowski, "Using ensembles of adaptive neuro-fuzzy inference system and optimization algorithms to predict reference evapotranspiration in subtropical climatic zones," Journal of Hydrology, vol. 2020, Article ID 125509, 2020.

[40] W. Feng, H. Lu, T. Yao, and Q. Yu, "Drought characteristics and its elevation dependence in the Qinghai-Tibet plateau during the last half-century," Scientific Reports, vol. 10, no. 1, p. 14323, 2020.

[41] S. Feng, H. Lu, P. Tian et al., "Analysis of microplastics in a remote region of the Tibetan Plateau: implications for natural environmental response to human activities," Science of The Total Environment, vol. 739, Article ID 140087, 2020.

[42] X. Han, D. Zhang, J. Yan, S. Zhao, and J. Liu, "Process development of flue gas desulphurization wastewater treatment in coal-fired power plants towards zero liquid discharge: energetic, economic and environmental analyses," Journal of Cleaner Production, vol. 261, Article ID 121144, 2020. 
[43] L. He, Y. Chen, H. Zhao, P. Tian, Y. Xue, and L. Chen, "Game-based analysis of energy-water nexus for identifying environmental impacts during Shale gas operations under stochastic input," Science of The Total Environment, vol. 627, pp. 1585-1601, 2018.

[44] L. He, J. Shen, and Y. Zhang, "Ecological vulnerability assessment for ecological conservation and environmental management," Journal of Environmental Management, vol. 206, pp. 1115-1125, 2018.

[45] J. Liu, Y. Liu, and X. Wang, "An environmental assessment model of construction and demolition waste based on system dynamics: a case study in Guangzhou," Environmental Science and Pollution Research, vol. 27, no. 30, pp. 37237-37259, 2020.

[46] H. Lu, P. Tian, and L. He, "Evaluating the global potential of aquifer thermal energy storage and determining the potential worldwide hotspots driven by socio-economic, geo-hydrologic and climatic conditions," Renewable and Sustainable Energy Reviews, vol. 112, pp. 788-796, 2019.

[47] S. Wang, K. Zhang, L. P. H. van Beek, X. Tian, and T. A. Bogaard, "Physically-based landslide prediction over a large region: scaling low-resolution hydrological model results for high-resolution slope stability assessment," Environmental Modelling \& Software, vol. 124, Article ID 104607, 2020.

[48] H. Chen, A. Chen, L Xu et al., "A deep learning CNN architecture applied in smart near-infrared analysis of water pollution for agricultural irrigation resources," Agricultural Water Management, vol. 240, Article ID 106303, 2020.

[49] Y. Chen, L. He, J. Li, and S. Zhang, "Multi-criteria design of shale-gas-water supply chains and production systems towards optimal life cycle economics and greenhouse gas emissions under uncertainty," Computers \& Chemical Engineering, vol. 109, pp. 216-235, 2018.

[50] Y. Chen, J. Li, H. Lu, and P. Yan, "Coupling system dynamics analysis and risk aversion programming for optimizing the mixed noise-driven shale gas-water supply chains," Journal of Cleaner Production, vol. 278, Article ID 123209, 2021.

[51] X. Cheng, L. He, H. Lu, Y. Chen, and L. Ren, "Optimal water resources management and system benefit for the Marcellus shale-gas reservoir in Pennsylvania and West Virginia," Journal of Hydrology, vol. 540, pp. 412-422, 2016.

[52] L. He, F. Shao, and L. Ren, "Sustainability appraisal of desired contaminated groundwater remediation strategies: an information-entropy-based stochastic multi-criteria preference model," Environment, Development and Sustainability, pp. 1-21, 2020.

[53] Q. Ma, R. Liang, R. Li, J. Feng, and K. Li, "Operational regulation of water replenishment to reduce supersaturated total dissolved gas in riverine wetlands," Ecological Engineering, vol. 96, pp. 162-169, 2016.

[54] Y. Ou, R. Li, B. R. Hodges, J. Feng, and C. Pu, "Impact of temperature on the dissipation process of supersaturated total dissolved gas in flowing water," Fresenius Environ. Bull, vol. 25, pp. 1927-1934, 2016.

[55] A. P. Piotrowski, M. Osuch, M. J. Napiorkowski, P. M. Rowinski, and J. J. Napiorkowski, "Comparing large number of metaheuristics for artificial neural networks training to predict water temperature in a natural river," Computers \& Geosciences, vol. 64, pp. 136-151, 2014.

[56] D. Tyrrell and K. George, "Finite element modelling of the hydrodynamics and water quality of the Patos Lagoon system, Brazil," Journal of Coastal Research, vol. 39, pp. 1594-1599, 2006.
[57] W. Yang, Y. Zhao, D. Wang, H. Wu, A. Lin, and L. He, "Using principal components analysis and IDW interpolation to determine spatial and temporal changes of surface water quality of Xinanjiang River in Huangshan, China," International Journal of Environmental Research and Public Health, vol. 17, no. 8, p. 2942, 2020.

[58] Q. Ma, R. Li, Q. Zhang, B. R. Hodges, J. Feng, and H. Yang, "Two-phase flow simulation of supersaturated total dissolved gas in the plunge pool of a high dam," Environmental Progress \& Sustainable Energy, vol. 35, no. 4, pp. 1139-1148, 2016.

[59] J.-j. Feng, R. Li, Q. Ma, and L.-1. Wang, "Experimental and field study on dissipation coefficient of supersaturated total dissolved gas," Journal of Central South University, vol. 21, no. 5, pp. 1995-2003, 2014.

[60] Z.-G. Li, H. Cheng, and T.-Y. Gu, "Research on dynamic relationship between natural gas consumption and economic growth in China," Structural Change and Economic Dynamics, vol. 49, pp. 334-339, 2019.

[61] E. Liu, L. Lv, Y. Yi, and P. Xie, "Research on the steady operation optimization model of natural gas pipeline considering the combined operation of air coolers and compressors," IEEE Access, vol. 7, pp. 83251-83265, 2019.

[62] J.-j. Feng, R. Li, H.-x. Yang, and J. Li, "A laterally averaged two-dimensional simulation of unsteady supersaturated total dissolved gas in deep reservoir," Journal of Hydrodynamics, vol. 25, no. 3, pp. 396-403, 2013.

[63] J. Huang, R. Li, J. Feng, W. Xu, and L. Wang, "Relationship investigation between the dissipation process of supersaturated total dissolved gas and wind effect," Ecological Engineering, vol. 95, pp. 430-437, 2016.

[64] Y. Ou, R. Li, Y. Tuo, J. Niu, J. Feng, and X. Pu, "The promotion effect of aeration on the dissipation of supersaturated total dissolved gas," Ecological Engineering, vol. 95, pp. 245-251, 2016.

[65] W. Perkins and M. Richmond, Modular Aquatic Simulation System in Two Dimensions Theory and Numerical Methods. Pacific Northwest National Laboratory Report, Pacific Northwest National Laboratory, Richland, WA, USA, 2004.

[66] X. Shen, R. Li, J. Huang et al., "Shelter construction for fish at the confluence of a river to avoid the effects of total dissolved gas supersaturation," Ecological Engineering, vol. 97, pp. $642-648,2016$. 